\title{
Millimeter of Mercury
}

National Cancer Institute

\section{Source}

National Cancer Institute. Millimeter of Mercury. NCI Thesaurus. Code C49670.

A non-SI unit of pressure equal to 133,332 Pa or 1.316E10-3 standard atmosphere. Use

of this unit is generally deprecated by ISO and IUPAC. 